\title{
Indeks Kesesuaian Wisata di Pantai Pasir Putih, Kabupaten Karangasem
}

\author{
I Komang Subandi a*, I Gusti Ngurah Putra Dirgayusa a , Abd. Rahman As-syakur a \\ a Program Studi Ilmu Kelautan, Fakultas Kelautan dan Perikanan, Universitas Udayana, Kampus UNUD Bukit Jimbaran, Bali 80361, Indonesia
}

*Penulis koresponden. Tel.: +62-85792674788

Alamat e-mail: ikomangsubandi@yahoo.com

Diterima (received) 15 Juni 2017; disetujui (accepted) 24 Agustus 2017; tersedia secara online (available online) 25 Agustus 2017

\begin{abstract}
The study of tourist suitability index (IKW) was conducted in Pasir Putih Beach, Bugbug Village, Karangasem Subdistrict, Karangasem district. Data was collected for 1 (one) month in January 2017 at 4 observation stations. Sources of primary data are obtained from observations and interviews with tourists and secondary data obtained from literature that related to agencies in Pasir Putih beach. Purposive sampling is used as a method for data collection. The data collected are incluted: coastal type, beach width, water depth, coastal slope, water base material, water flow velocity, waters brightness, coastal closure, harmful biota, and freshwater availability. The analysis of IKW for recreation beach category refers to the matrix of tourism and tourism conformity classification. The limiting factor of IKW in Pasir Putih Beach is coastal land cover and wide beach. IKW value for tourism activities in the beach recreation category at Pasir Putih Beach at station I of $94.23 \%$, II of $96.79 \%$, III by $85.89 \%$, and VI of $81.41 \%$. All stations are categorized as suitable (SS) for coastal tourism activities. Zone utilization coastal tourist area for swimming and sunbathing done at station I and II. Zone utilization area for recreation of a walk are station I, II, III, and IV. Station IV at south area including zone of sacred area.
\end{abstract}

Keywords: IKW; zoning utilization; Pasir Putih Beach

\begin{abstract}
Abstrak
Penelitian indek kesesuaian wisata (IKW) dilaksanakan di kawasan Pantai Pasir Putih, Desa Bugbug, Kecamatan Karangasem, Kabupaten Karangasem. Pengambilan data dilakukan selama 1 (satu) bulan pada bulan Januari Tahun 2017 di 4 stasiun pengamatan. Sumber data penelitian ini dari data primer yang diperoleh dari observasi dan wawancara dengan wisatawan dan data sekunder diperoleh dari studi literatur atau dari instansi terkait di Pantai Pasir putih.Pengambilan data dilakukan dengan cara purposive sampling. Data yang diambil meliputi: tipe pantai, lebar pantai, kedalaman perairan, kemiringan pantai, material dasar perairan, kecepatan arus perairan, kecerahan perairan, penutupan lahan pantai, biota berbahaya, dan ketersediaan air tawar. Analisis IKW pantai kategori rekreasi mengacu pada matriks kesesuaian wisata dan klasifikasi kesesuaian wisata. Faktor pembatas pada IKW di Pantai Pasir Putih adalah tutupan lahan pantai dan lebar pantai. Nilai IKW untuk kegiatan wisata kategori rekreasi pantai di Pantai Pasir Putih pada stasiun I sebesar 94.23\%, II sebesar 96.79\%, III sebesar $85.89 \%$, dan VI sebesar $81.41 \%$. Semua stasiun termasuk kategori sangat sesuai (SS) untuk kegiatan wisata pantai. Zona pemanfaatankawasan wisata pantai untuk berenang dan berjemur dilakukan pada stasiun I dan II. Zona pemanfaatan kawasan untuk rekreasi pantai dilakukan pada stasiun I, II, III, dan IV. Stasiun IVarea bagian selatan termasuk zona kawasan suci.
\end{abstract}

Kata Kunci: IKW; zonasi pemanfaatan; Pantai Pasir Putih

\section{Pendahuluan}

Indeks kesesuaian wisata (IKW) menunjukan penilaian suatu kawasan mengenai tingkat kelayakan/kesesuaian untuk dijadikan suatu objek wisata. Kesesuaian wisata ini sangat diperlukan untuk pengembangan kawasan wisata yaitu untuk melakukan perkiraan dampak lingkungan, pengendalian dan pembatasan pengelolaan, sehingga tujuan wisata menjadi selaras 
(Mutmainah et al., 2016). Suatu kawasan wisata menarik secara visual belum bisa dikatakan baik dan sesuai secara ekologi, masih harus mempertimbangkan dan menguji beberapa parameter fisik dan biologi. Sehingga diperlukan Indeks kesesuaian wisata sebagai data pendukung untuk pengembangan suatu kawasan wisata menjadi keberlanjutan.

Pulau Bali salah satu provinsi di Indonesia yang memiliki destinasi wisata yang terkenal karena budaya, adat istiadat, kesenian yang beraneka ragam serta keindahan alam seperti pegunungan dan pantai (Hakim et al., 2009; Law et al., 2016). Kawasan pantai di Bali menjadi kunci utama dalam kegiatan wisata baik wisata air maupun wisata daratan seperti selancar, water sport, rekeasi, olahraga dan lainnya (Henderson and Smith, 2009). Paradigma kegiatan pemanfaatan kawasan wisata pantai saat ini lebih mengutamakan pada keuntungan ekonomi, yaitu bagaimana menarik wisatawan sebanyakbanyaknya tanpa memperhatikan lingkungan yang ada (Yulianda, 2007; Sobocinska, 2011). Akibatnya akan terjadi degradasi atau penurunan kualitas lingkungan karena pemanfaatan melebihi batas tolerasi (Sutawa, 2012; Buckley, 2012). Selain itu, berkembangnya pemanfaatan kawasan wisata pantai yang dikelola oleh masyarakat dan investor kurang memperhatikan keberlanjutan wisata dan kebudayaan daerah sehingga perlu dilakukan pengkajian mengenai tingkat kesesuaian wisata pantai.

Desa Bugbug, Kecamatan Karangasem termasuk dalam kawasan strategis pariwisata Kabupaten Karangasem (Perda Kabupaten Karangasem tentang RTRW Kabupaten Karangasem, 2012). Desa Bugbug memiliki daerah pantai yang cukup luas, indah, dan pasir berwarna putih, tapi belum dimanfaatkan secara optimal. Pantai tersebut adalah pantai Pasir Putih yang sedang berkembang sebagai wisata pantai. Potensi pantai Pasir Putih yang cukup baik akan dapat dijadikan sebagai salah satu sumber pendapatan bagi masyarakat dan juga pemerintah. Beberapa kegiatan wisatawan yang dilakukan adalah jalanjalan, berenang, dan berjemur. Kegiatan wisatawan tersebut harus didukung dari keamanan dan kenyamanan lingkungan, misalnya terlindung biota berbahaya. Selain itu, pemanfaatan kawasan pantai harus memperhatikan kemampuan alam dalam mentolelir gangguan yang timbul dan standar keaslian sumberdaya alam (Yulisa et al., 2016). Sehingga pengembangan kawasan wisata ini harus
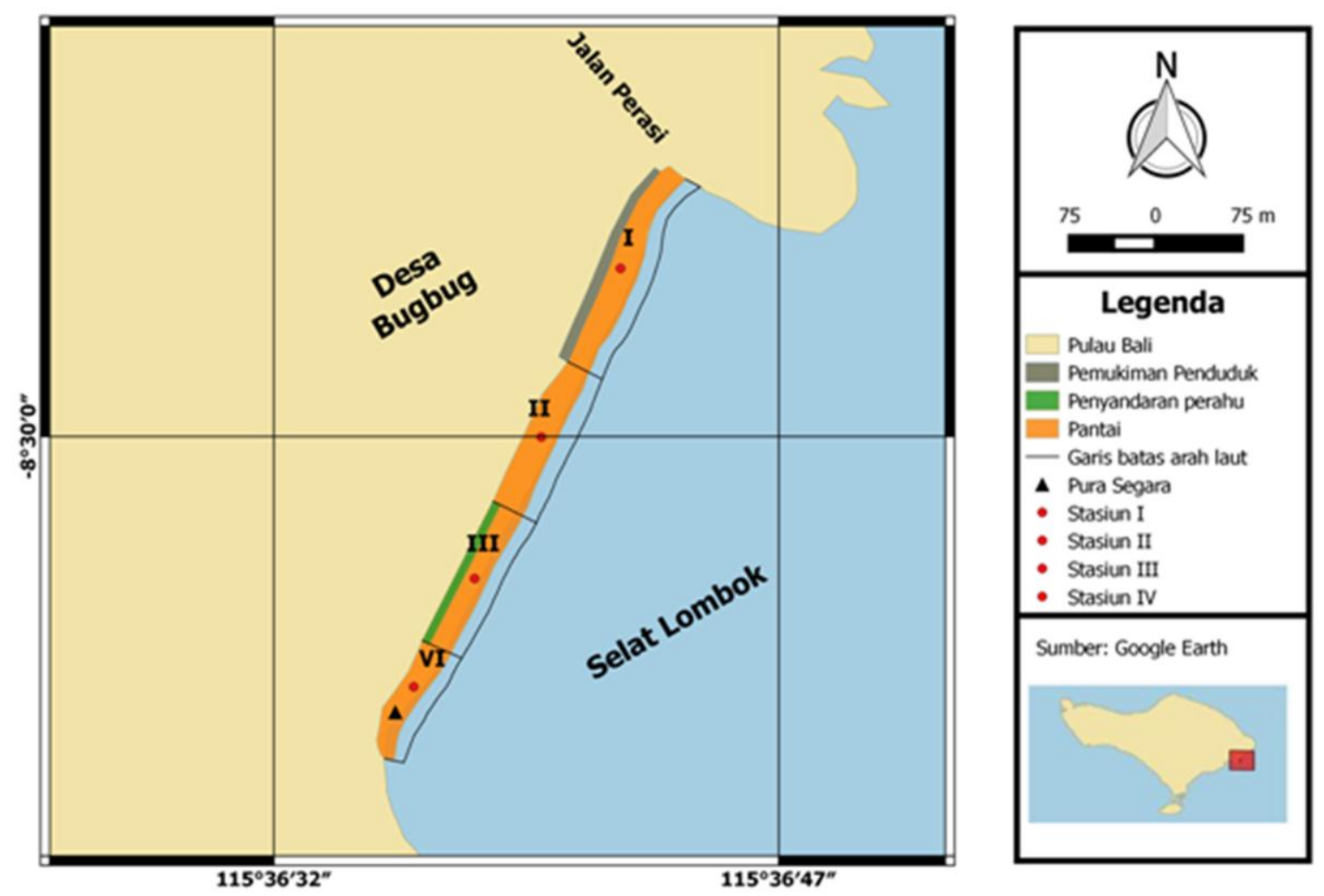

Gambar 1. Lokasi penelitian di Pantai Pasir Putih 
mengarah pada pengembangan yang terencana sehingga dapat diperoleh manfaat yang optimal bagi masyarakat.

Adapun tujuan dari penelitian yaitu untuk menentukan faktor-faktor pembatas indeks kesesuaian wisata (IKW), indeks kesesuaian wisata (IKW), dan menentukan zona pemanfaatan wisata di kawasan pantai Pasir Putih di Desa Bugbug, Kecamatan Karangasem.

\section{Metode Penelitian}

\subsection{Waktu dan Tempat Penelitian}

Penelitian ini dilaksanakan di kawasan pantai Pasir Putih, Desa Bugbug, Kecamatan Karangasem, Kabupaten Karangasem. Penelitian di lakukan selama 1 (satu) bulan pada bulan Januari Tahun 2017. Adapun peta lokasi penelitian yang dapat disajikan pada Gambar 1.

\subsection{Alat dan Bahan}

Alat dan bahan dalam penelitian ini digunakan untuk mengambil data primer. Alat dan bahan yang digunakan yaitu: Rol meter, Tongkat skala, Egman Grab, Drift pool, ADS dan GPS.

\subsection{Metode Penelitian}

\subsubsection{Sumber Data}

Sumber data dalam penelitian ini yaitu data primer dan data sekunder. Data primer diperoleh melalui pengamatan langsung pada lokasi penelitian dititik pengambilan sampel yang telah ditentukan berupa observasi dan wawancara dengan wisatawan dan pihak yang terkait di lokasi penelitian. Data sekunder adalah data yang dikumpulkan atau diperoleh dari studi literatur atau dari instansi terkait yang berhubungan dengan permasalahan penelitian.

Tabel 1

Matriks indeks kesesuaian wisata pantai kategori rekreasi

\begin{tabular}{|c|c|c|c|c|c|c|c|c|c|c|}
\hline \multirow{2}{*}{ No. } & \multirow{2}{*}{ Parameter } & \multirow{2}{*}{ Bobot } & \multicolumn{8}{|c|}{ Skor dan Kategori } \\
\hline & & & Kategori & Skor & Kategori & Skor & Kategori & Skor & Kategori & Skor \\
\hline 1. & Tipe Pantai & 5 & $\begin{array}{l}\text { Pasir } \\
\text { putih }\end{array}$ & 5 & $\begin{array}{l}\text { Pasir } \\
\text { putih, } \\
\text { sedikit } \\
\text { karang }\end{array}$ & 5 & $\begin{array}{l}\text { Pasir } \\
\text { hitam, } \\
\text { berkarag, } \\
\text { sedikit } \\
\text { terjal }\end{array}$ & 5 & $\begin{array}{l}\text { Lumpur, } \\
\text { berbatu, } \\
\text { terjal }\end{array}$ & 5 \\
\hline 2. & $\begin{array}{l}\text { Lebar } \\
\text { Pantai(m) }\end{array}$ & 5 & $>15$ & 5 & $10-15$ & 5 & $3-<10$ & 5 & $<3$ & 5 \\
\hline 3. & $\begin{array}{l}\text { Kedalaman } \\
\text { perairan(m) }\end{array}$ & 5 & $0-3$ & 5 & $>3-6$ & 5 & $>6-10$ & 5 & $>10$ & 5 \\
\hline 4. & $\begin{array}{l}\text { Material Dasar } \\
\text { Perairan }\end{array}$ & 4 & Pasir & 4 & $\begin{array}{l}\text { Karang } \\
\text { berpasir }\end{array}$ & 4 & $\begin{array}{l}\text { Pasir } \\
\text { berlump } \\
\text { ur }\end{array}$ & 4 & Lumpur & 4 \\
\hline 5. & $\begin{array}{l}\text { Kemiringan } \\
\text { Pantai }\left(^{\circ}\right)\end{array}$ & 4 & $<10$ & 4 & $10-25$ & 4 & $>25-45$ & 4 & $>45$ & 4 \\
\hline 6. & $\begin{array}{l}\text { Kecepatan } \\
\text { Arus(m/dt) }\end{array}$ & 4 & $0-0.17$ & 4 & $\begin{array}{l}>0.17- \\
0.34\end{array}$ & 4 & $\begin{array}{l}>0.34- \\
0.51\end{array}$ & 4 & $>0.51$ & 4 \\
\hline 7. & $\begin{array}{l}\text { Kecerahan } \\
\text { Perairan (m) }\end{array}$ & 3 & $>10$ & 3 & $>5-10$ & 3 & $3-5$ & 3 & $<3$ & 3 \\
\hline 8. & $\begin{array}{l}\text { Penutupan } \\
\text { Lahan Pantai }\end{array}$ & 3 & $\begin{array}{l}\text { Lahan } \\
\text { terbuka, } \\
\text { kelapa }\end{array}$ & 3 & $\begin{array}{l}\text { Semak, } \\
\text { belukar } \\
\text { rendah, } \\
\text { savana }\end{array}$ & 3 & $\begin{array}{l}\text { Belukar } \\
\text { tinggi }\end{array}$ & 3 & $\begin{array}{l}\text { Hutan } \\
\text { bakau, } \\
\text { pemukiman, } \\
\text { pelabuhan }\end{array}$ & 3 \\
\hline 9. & $\begin{array}{l}\text { Biota } \\
\text { Berbahaya }\end{array}$ & 3 & $\begin{array}{l}\text { Tidak } \\
\text { ada }\end{array}$ & 3 & $\begin{array}{l}\text { Bulu } \\
\text { Babi }\end{array}$ & 3 & $\begin{array}{l}\text { Bulu } \\
\text { Babi, } \\
\text { Ikan Pari }\end{array}$ & 3 & $\begin{array}{l}\text { Bulu Babi, } \\
\text { Ikan Pari, } \\
\text { lepu dan } \\
\text { Hiu }\end{array}$ & 3 \\
\hline 10. & $\begin{array}{l}\text { Kesediaan Air } \\
\text { Tawar }(\mathrm{km})\end{array}$ & 3 & $<0.5$ & 3 & $0.5-1$ & 3 & $>1-2$ & 3 & $>2$ & 3 \\
\hline
\end{tabular}




\subsubsection{Metode Pengambilan Data}

Pengambilan data di kawasan pantai Pasir Putih dilakukan dengan cara purposive sampling. Purposive sampling yaitu teknik pengambilan sampel secara sengaja dan sudah ditentukan sehingga yang ingin diteliti dapat terwakili (Fachrul, 2007). Data yang diambil meliputi: tipe pantai, lebar pantai, kedalaman perairan, kemiringan pantai, material dasar perairan, kecepatan arus perairan, kecerahan perairan, penutupan lahan pantai, biota berbahaya, dan ketersediaan air tawar.

\section{$2.4 \quad$ Analisis Data}

\subsubsection{Analisis Kesesuaian Wisata Pantai}

Analisis kesesuaian yang dilakukan dalam penelitian ini hanya fokus pada peruntukan kawasan wisata pantai kategori rekreasi. Kesesuaian wisata pantai mempertimbangkan 10 parameter yakni kedalaman perairan, tipe pantai, lebar pantai, material dasar perairan, kecepatan arus perairan, kemiringan pantai, kecerahan perairan, penutupan lahan pantai, biota berbahaya dan ketersediaan air tawar seperti diperlihatkan pada Tabel 1. Matrik indeks keseseaian wisata pantai kategori rekreasi mengacu pada matriks kesesuaian Yulianda (2007).

Penyusunan matriks indeks kesesuaian wisata pantai meliputi peruntukan wisata pantai kategori rekreasi. Matriks tersebut untuk mengetahui parameter yang menjadi indikator kesesuaian melalui pembobotan dan skoring pada setiap parameter. Pembobotan pada setiap faktor pembatas/parameter ditentukan berdasarkan pada dominannya parameter tersebut terhadap wisata pantai. Pemberian skor ditujukan untuk menilai beberapa faktor pembatas terhadap suatu evaluasi kesesuaian (Yusuf, 2007).

Nilai maksimum pada matrik indeks kesesuaian wisata pantai tersebut adalah 156, dimana nilai tersebut merupakan hasil penjumlahan dari perkalian masing-masing bobot dengan skor maksimum. Menurut Yulianda (2007) rumus yang digunakan untuk nilai IKW yaitu:

$$
I K W=\frac{\sum N i}{N M a k s} \times 100 \%
$$

Keterangan:

IKW : Indeks Kesesuaian Wisata

$\mathrm{Ni} \quad$ : Nilai Paramater ke-i (Bobot $x$ Skor)

Nmaks : Nilai Maksimum wisata (156)

Berdasarkan matriks indeks kesesuaian wisata pantai kategori rekreasi tersebut selanjutnya akan dilakukan penyusunan kelas kesesuaian wisata pantai. Kelas kesesuaian tersebut mempunyai rentang/interval kelas tergantung dari jumlah kelas kesesuaian pantai, total skor minimum dan total skor maksimum. Menurut Yusuf, (2007) interval kelas kesesuaian wisata dihitung dengan menggunakan rumus sebagai berikut:

$$
R K=\frac{\text { TSMak }- \text { TSMin }}{\text { Jumlahkelas }}
$$

Keterangan:

RK : Rentang/interval kelas kesesuaian wisata pantai

Nmak : Nilai Maksimum wisata pantai (156)

Nmin : Nilai Minimum wisata pantai (39)

Interval kelas kesesuaian wisata memiliki 4 (empat) klasifikasi penilaian. Adapun 4 (empat) klasifikasi penilaian kesesuaian wisata pada Tabel 2 sebagai berikut:

\subsubsection{Penentuan Zona Pemanfaatan Kawasan Pantai}

Pembagian zona pemanfaatan di Pantai Pasir Putih dilakukan berdasarkan kegiatan wisata yang ditemukan di wilayah tersebut dan dibandingkan dengan parameter indeks kesesuaian wisata. Batasan zona dilakukan dengan pengambilan data koordinat menggunakan GPS yang selanjutnya diplot ke dalam peta. Pemetaan dilakukan dengan pendekatan Sistem Informasi Geografis (SIG) menggunakan program QGIS 2.8.

\section{Tabel 2}

Klasifikasi penilaian kesesuaian wisata pantai kategori rekreasi

\begin{tabular}{lll}
\hline No. & \multicolumn{1}{c}{ Klasifikasi } & \multicolumn{1}{c}{ Nilai } \\
\hline 1. & Sangat sesuai (SS) & $81-100 \%$ \\
2. & Sesuai (S) & $63-<81 \%$ \\
3. & Sesuai bersyarat & $44-<63 \%$ \\
& (SB) & $<44 \%$ \\
\hline
\end{tabular}

Sumber : Yusuf, 2007 


\section{Hasil dan Pembahasan}

\subsection{Faktor-faktor Pembatas Indeks Kesesuaian Wisata (IKW)}

Adapun beberapa faktor yang mempengaruhi nilai dari Indeks Kesesuaian Wisata (IKW). IKW mempertimbangkan 10 faktor yakni kedalaman perairan, tipe pantai, lebar pantai, material dasar perairan, kecepatan arus perairan, kemiringan pantai, kecerahan perairan, penutupan lahan pantai, biota berbahaya dan ketersediaan air tawar. Faktor tersebut sebagai berikut:

\subsubsection{Tipe Pantai}

Berdasarkan hasil observasi secara visual di lapangan pada masing-masing stasiun pengamatan didapatkan hasil yang disajikan padaTabel 3.

\section{Tabel 3}

Kesesuaian Tipe Pantai pada stasiun I, II, III, dan IV

\begin{tabular}{lll}
\hline Stasiun & \multicolumn{1}{c}{ Tipe Pantai } & \multicolumn{1}{c}{$\begin{array}{c}\text { Kategori } \\
\text { Kesesuaian }\end{array}$} \\
\hline I & Pasir Putih & Sangat Sesuai \\
II & Pasir Putih & Sangat Sesuai \\
III & Pasir Putih Sedikit & Sesuai \\
IV & Batuan Karang & Sangat Sesuai \\
\hline
\end{tabular}

Hasil observasi dan pengamatan secara visual tipe pantai pada masing-masing stasiun di pantai Pasir Putih merupakan pasir putih. Namun, pada stasiun III tergolong tipe pantai pasir putih sedikit batuan karang. Berdasarkan matriks kesesuaian wisata, stasiun I, II, dan IV tergolong dalam kategori S1 (Sangat Sesuai) untuk kegiatan wisata pantai dan stasiun III tergolong dalam kategori S2 (Sesuai). Penelitian Ardian et. al., (2015) mengatakan kawasan pantai berpasir putih baik untuk dilakukan kegiatan wisata pantai seperti rekreasi, jalan-jalan.

Hamparan pasir putih memberikan kesan tersendiri bagi wisatawan yang berkunjung ke Pantai Pasir Putih untuk kegiatan wisata pantai. Pantai pasir putih sangat diminati oleh wisatawan karena dapat memberikan nilai estitika bagi pantai itu sendiri. Mukhtar et al., (2016) menyatakan bahwa pantai berpasir atau didominasi oleh substrat pasir akan sangat baik untuk pariwisata pantai, dibandingkan dengan pantai yang berbatu dan berlumpur karena dapat menggangu kenyamanan wisatawan.

\subsubsection{Lebar Pantai}

Berdasarkan hasil pengukuran pada masingmasing stasiun pengamatan didapatkan bahwa lebar pantai pada stasiun I yaitu $16.93 \mathrm{~m}$, stasiun II yaitu $14.61 \mathrm{~m}$, stasiun III yaitu $13.68 \mathrm{~m}$, dan stasiun IV yaitu $9.73 \mathrm{~m}$. Berdasarkan matrik kesesuaian wisata satasiun I termasuk dalam kesesuaian S1 (Sangat Sesuai). Pada stasiun II, dan III termasuk dalam kategori kesesuaian S2 (Sesuai) sedangkan stasiun IV tergolong dalam kategori S3 (Sesuai Bersyarat). Nilai dari kesesuaian lebar pantai dapat dilihat pada Tabel 4.

Tabel 4

Kesesuaian Lebar Pantai pada stasiun I, II, III, dan IV

\begin{tabular}{lll}
\hline Stasiun & \multicolumn{1}{c}{ Lebar Pantai $(\mathrm{m})$} & \multicolumn{1}{c}{$\begin{array}{c}\text { Kategori } \\
\text { Kesesuaian }\end{array}$} \\
\hline I & 16.93 & Sangat Sesuai \\
II & 14.61 & Sesuai \\
III & 13.68 & Sesuai \\
IV & 9.73 & Sesuai Bersyarat \\
\hline
\end{tabular}

Kawasan Pantai Pasir Putih memiliki lebar pantai $13.7 \mathrm{~m}$ dan panjang pantai $645 \mathrm{~m}$. Sehingga sangat memungkinkan untuk melakukan aktivitas disepanjang Pantai Pasir Putih seperti berjemur, jalan-jalan, dan sarana bermain bagi anak-anak di ombak. Panjang garis pantai dan lebar pantai yang cukup panjang dengan hamparan pasir sangat memungkinkan untuk melakukan aktivitas di sepanjang pantai.

\subsubsection{Kedalaman Perairan}

Hasil pengukuran kedalaman perairan Pantai Putih Putih menunjukan kedalaman perairan relatif dangkal. Pada stasiun I kedalaman perairan antara 0.91-1.12 m, stasiun II antara 1.10-1.11 m, stasiun III antara 1.60-3.10 m, dan stasiun IV yaitu 2.11-3.14 m. Kesesuaian kedalaman perairan dapat ditampilkan pada Tabel 5.

Berdasarkan matriks kesesuaian kedalaman perairan pada stasiun I dan II termasuk dalam 
kategori kesesuaian S1 (Sangat Sesuai) dan stasiun III dan IV termasuk dalam kategori kesesuaian S2 (Sesuai). Kedalaman perairan di Pantai Pasir Putih baik untuk dijadikan wisata pantai terutama mandi dan berenang. Hal ini sesuai dengan penelitian Cahyadinata (2009); Juliana, et al., (2013) mengatakan bahwa kesesuaian kawasan pantai untuk kedalaman adalah berkisar antara $<3$ $m$ dengan kategori sangat sesuai sebagai wisata mandi dan berenang. Kedalaman perairan sangat penting untuk kenyamanan dan keamanan wisatawan yang melakukan kegiatan wisata mandi dan berenang.

\section{Tabel 5}

Kesesuaian Kedalaman Perairan pada stasiun I, II, III, dan IV

\begin{tabular}{lll}
\hline Stasiun & Kedalaman Perairan $(\mathrm{m})$ & $\begin{array}{c}\text { Kategori } \\
\text { Kesesuaian }\end{array}$ \\
\hline I & $0.91-1.12$ & Sangat Sesuai \\
II & $1.10-1.11$ & Sangat Sesuai \\
III & $1.60-3.10$ & Sesuai \\
IV & $2.11-3.14$ & Sesuai \\
\hline
\end{tabular}

\subsubsection{Material Dasar Perairan}

Hasil pengamatan mengenai material dasar perairan dilapangan dapat dilihat pada Tabel 6 . Pantai Pasir Putih memiliki material dasar perairan/ substrat berbeda antar stasiun pengamatan. Pada stasiun I dan II material dasar perairan berupa pasir termasuk dalam kategori kesesuaian S1 (Sangat Sesuai). Pada stasiun III dan IV memiliki materia dasar perairan berupa karang berpasir termasuk dalam kategori kesesuaian S2 (Sesuai).

\section{Tabel 6}

Kesesuaian Material Dasar Perairanpada stasiun I, II, III, dan IV

\begin{tabular}{lll}
\hline Stasiun & Materia Dasar Perairan & $\begin{array}{c}\text { Kategori } \\
\text { Kesesuaian }\end{array}$ \\
\hline I & Pasir & Sangat Sesuai \\
II & Pasir & Sangat Sesuai \\
III & Karang Berpasir & Sesuai \\
IV & Karang Berpasir & Sesuai \\
\hline
\end{tabular}

Berdasarkan hasil kesesuaian tersebut, secara umum material dasar perairan masih baik dan mendukung kegitan wisata pantai seperti berenang dan rekreasi. Hasil penelitian Muflih et al., (2015) bahwa material dasar perairan berupa pasir berwarna putih sangat sesuai untuk dijadikan wisata rekreasi dan berenang.

\subsubsection{Penutupan Lahan Pantai}

Berdasarkan hasil pengamatan penutupan lahan pantai yang telah dilakukan di Pantai Pasir Putih ditemukan beragam jenis tumbuhan pantai (Tabel 7). Stasiun I penutupan lahan pantai berupa perumahan, restoran dan artshop yang termasuk kategori N (Tidak Sesuai). Pada stasiun II penutupan lahan pantai berupa lahan terbuka dan pohon Kelapa termasuk dalam kategori kesesuaian S1 (Sangat Sesuai). Pada stasiun III penutupan lahan pantai berupa semak belukar rendah dan Perahu (Jukung) termasuk dalam kategori S2 (Sesuai). Sedangkan pada stasiun IV terdapat semak belukar tinggi (Kaktus, Ketapang, Gamal, dan Kapuk) yang merupakan termasuk dalam kategori S3 (Sesuai Bersyarat).

\section{Tabel 7}

Kesesuaian Penutupan Lahan Pantai pada stasiun I, II, III, dan IV

\begin{tabular}{lll}
\hline Stasiun & Penutupan Lahan Pantai & \multicolumn{1}{c}{$\begin{array}{c}\text { Kategori } \\
\text { Kesesuaian }\end{array}$} \\
\hline I & $\begin{array}{l}\text { Perumahan, Restauran } \\
\text { dan Artshop }\end{array}$ & Tidak Sesuai \\
II & $\begin{array}{l}\text { Lahan Terbuka dan } \\
\text { Pohon Kelapa }\end{array}$ & Sangat Sesuai \\
III & $\begin{array}{l}\text { Semak Belukar Rendah } \\
\text { danPerahu (Jukung) }\end{array}$ & Sesuai \\
& $\begin{array}{l}\text { Semak belukar Tinggi } \\
\text { (Kaktus, Ketapang, } \\
\text { IV }\end{array}$ & $\begin{array}{l}\text { Sesuai } \\
\text { Gersal, dan Kapuk) }\end{array}$ \\
\hline
\end{tabular}

Semak belukar rendah yang terdapat di stasiun III yaitu tumbuhan Batata Pantai (Ipomoea pescaprae). Penutupan lahan pantai pada staiun III dan IV dapat direhabilitasi dengan cara melakukan pembabatan pada semak belukar rendah dan tinggi, sehingga kesesuaian wisata menjadi sangat sesuai dan dapat mendukung kegiatan wisata pantai. 


\subsubsection{Biota Berbahaya}

Berdasarkan pengamatan di stasiun pengamatan pada stasiun I, II, III, dan IV tidak ditemukan biota berbahaya. Kesesuaian biota berbahaya dapat dilihat pada Tabel 8.

Berdasarkan matriks kesesuaian, semua stasiun termasuk kategori S1 (Sangat Sesuai). Selain itu, berdasarkan 15 responden yang diwawancara $100 \%$ mengatakan bahwa tidak ditemukan biota berbahaya. Hal ini diduga karena tidak ditemukannya vegetasi lamun di Pantai Pasir Putih yang dimanfaatkan bulu babi (Diadema sp) sebagai habitat dan sebagai makanan utamanya.

Tabel 8

Kesesuaian Biota Berbahaya pada stasiun I,II, III, dan IV

\begin{tabular}{llc}
\hline Stasiun & Biota Berbahaya & $\begin{array}{c}\text { Kategori } \\
\text { Kesesuaian }\end{array}$ \\
\hline I & Tidak Ada & Sangat Sesuai \\
II & Tidak Ada & Sangat Sesuai \\
III & Tidak Ada & Sangat Sesuai \\
IV & Tidak Ada & Sangat Sesuai \\
\hline
\end{tabular}

\subsubsection{Kecerahan Perairan}

Kecerahan perairan dalam kaitannya dengan kegiatan ekowisata pantai sangat berperan dalam hal kenyamanan para wisatawan pada saat berenang. Kecerahan pantai Pasir Putih dapat dilihat pada Tabel 9.

Berdasarkan hasil pengukuran di lapangan kecerahan di perairan Pantai Pasir Putih pada stasiun I, II, III, dan IV yaitu $>10 \mathrm{~m}$. Hasil ini masuk dalam kategori kesesuaian S1 (Sangat Sesuai). Keadaan perairan di Pantai Pasir Putih sangat jernih dan jarak pandang untuk kegiatan berenang masih sangat mendukung. Selain itu, kecerahan perairan juga sangat berpengaruh terhadap kenyamanan wisatawan dalam melakukan kegiatan mandi dan renang.

\subsubsection{Kecepatan Arus}

Pengukuran kecepatan arus dilakukan pada saat pasang menuju surut. Hasil pengukuran terhadap kecepatan arus di Pantai Pasir Putih pada stasiun I yaitu $0.087 \mathrm{~m} / \mathrm{det}$, stasiun II yaitu $0.077 \mathrm{~m} / \mathrm{det}$, stasiun III yaitu $0.07 \mathrm{~m} /$ det dan IV $0.08 \mathrm{~m} / \mathrm{det}$ (Tabel 10). Kecepatan arus pada semua stasiun pengamatan termasuk S1 (Sangat Sesuai) dan tidak membahayakan wisatawan yang melakukan kegiatan wisata (mandi dan renang) di Pantai Pasir Putih.

Tabel 9

Kesesuaian Kecerahan Perairan pada stasiun I, II, III, dan IV

\begin{tabular}{llll}
\hline Stasiun & & $\begin{array}{c}\text { Kecerahan } \\
\text { Perairan }(\mathrm{m})\end{array}$ & Kategori Kesesuaian \\
\hline I & $>10$ & & Sangat Sesuai \\
II & $>10$ & Sangat Sesuai \\
III & $>10$ & Sangat Sesuai \\
IV & $>10$ & Sangat Sesuai \\
\hline
\end{tabular}

Tabel 10

Kesesuaian Kecepatan Arus pada stasiun I, II, III, dan IV

\begin{tabular}{lcc}
\hline Stasiun & $\begin{array}{c}\text { Kecepatan Arus } \\
(\mathrm{m} / \mathrm{det})\end{array}$ & $\begin{array}{c}\text { Kategori } \\
\text { Kesesuaian }\end{array}$ \\
\hline I & 0.087 & Sangat Sesuai \\
II & 0.077 & Sangat Sesuai \\
III & 0.07 & Sangat Sesuai \\
IV & 0.08 & Sangat Sesuai \\
\hline
\end{tabular}

Kecepatan arus di Perairan Pantai Pasir Putih cenderung sama antar stasiun satu dengan yang lainnya, hal ini karena peraiaran tersebut tidak terlalu luas dan berada dicekungan daratan yang di apit oleh dua gugusan batuan karang.

\subsubsection{Kemiringan Pantai}

Kemiringan pantai merupakan tingkat kelandaian dan kedataran suatu kawasan pantai. Kemiringan pantai pada suatu kawasan wisata cenderung mempengaruhi keamanan seseorang untuk melakukan kegiatan wisata pantai seperti bermain pasir dan bermain-main dengan ombak ditepian pantai.

Berdasarkan hasil pengukuran kemiringan pantai pada stasiun I, II, III, dan IV yaitu $7^{\circ}, 8^{\circ}, 7^{\circ}$, dan $11^{\circ}$ (Tabel 11). Pada stasiun I, II, dan III 
termasuk dalam kategori kesesuaian S1 (Sangat Sesuai) dan termasuk kategori pantai datar. Pada stasiun IV termsuk dalam kategori kesesuaian S2 (Sesuai) dan termasuk dalam kategori pantai landai. Pantai datar sampai landai sangat baik untuk kegiatan wisata renang dimana wisatawan dapat melakukan berbagai kegiatan seperti berenang, bermain pasir serta dapat bermain-main dengan ombak di tepinya.

\section{Tabel 11}

Kesesuaian Kemiringan Pantai pada stasiun I, II, III, dan IV

\begin{tabular}{lll}
\hline Stasiun & $\begin{array}{c}\text { Kemiringan } \\
\text { Pantai }\left({ }^{\circ}\right)\end{array}$ & Kategori Kesesuaian \\
\hline I & 7 & Sangat Sesuai \\
II & 8 & Sangat Sesuai \\
III & 7 & Sangat Sesuai \\
IV & 11 & Sesuai \\
\hline
\end{tabular}

\subsubsection{Ketersediaan Air Tawar}

Ketersediaan air tawar menjadi komponen utama di kawasan wisata pantai. Sumber air tawar di Pantai Pasir Putih terletak dekat dengan pemukiman penduduk. Keadaan sumur tersebut cukup terawat dan dikelola dengan baik, hal ini karena warga setempat menggunakan air sumur untuk memenuhi kebutuhan sehari-hari.

Berdasarkan hasil penelitian di lapangan jarak kawasan pantai dengan ketersediaan air tawar pada masing-masing yaitu stasiun I yaitu 0.055$0.164 \mathrm{~km}$, tasiun II sebesar $0.051-0.122 \mathrm{~km}$, stasiun III sebesar $0.046-0.087 \mathrm{~km}$, dan stasiun IV sebesar 0.053-0.132 Km. Dengan demikian stasiun I, II, III, dan IV termasuk dalam kategori kesesuaian S1 (Sangat Sesuai) (Tabel 12).

\section{Tabel 12}

Kesesuaian Ketersediaan Air Tawar pada stasiun I, II, III, dan IV

\begin{tabular}{lll}
\hline Stasiun & $\begin{array}{c}\text { Jarak Ketersediaan } \\
\text { Air Tawar }(\mathrm{Km})\end{array}$ & $\begin{array}{c}\text { Kategori } \\
\text { Kesesuaian }\end{array}$ \\
\hline I & $0.055-0.164$ & Sangat Sesuai \\
II & $0.051-0.122$ & Sangat Sesuai \\
III & $0.046-0.087$ & Sangat Sesuai \\
IV & $0.053-0.132$ & Sangat Sesuai \\
\hline
\end{tabular}

Ketersediaan air tawar penting bagi wisatawan terutama bagi yang melakukan kegiatan wisata
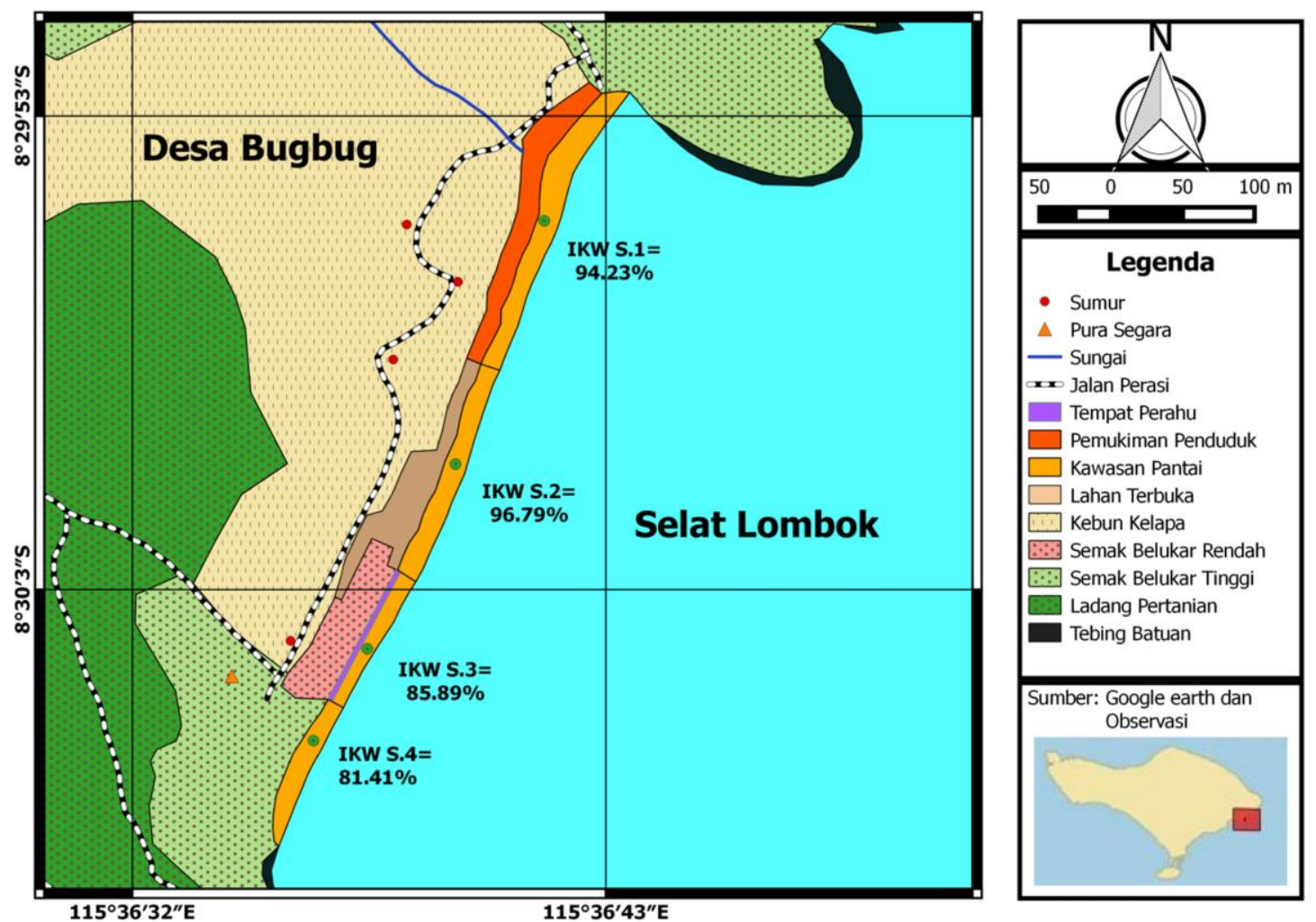

Gambar 2. Indeks Kesesuaian Wisata (IKW) di Pantai Pasir Putih 


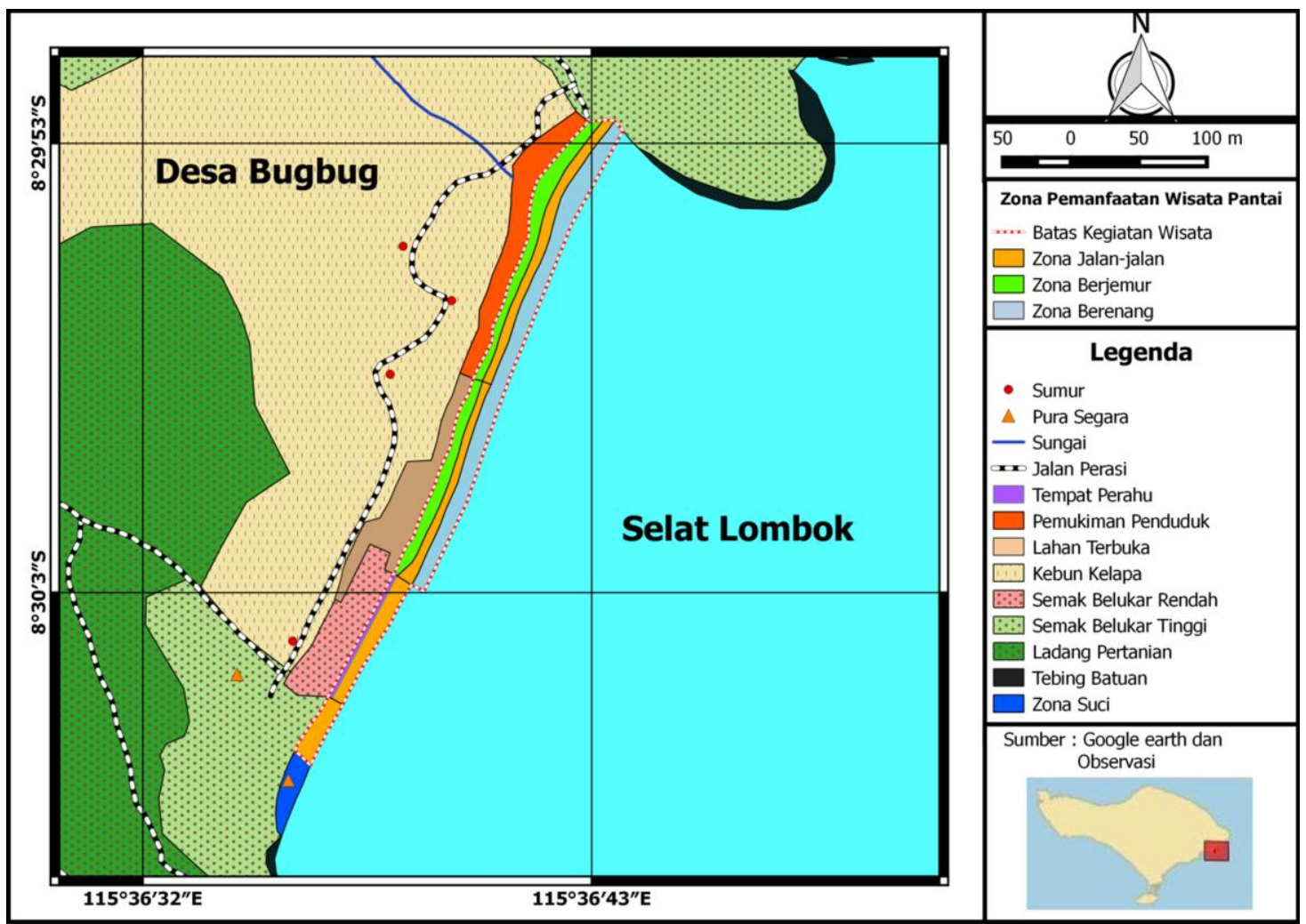

Gambar 3. Zona Pemanfaatan Kawasan Pantai di Pantai Pasir Putih

mandi dan berenang karena air tawar digunakan untuk membilas sisa air laut. Hal ini sesuai dengan pendapat Saputra and Khodijah (2013) menyatakan bahwa saat melakukan kegiatan wisata, ketersediaan air bersih berupa air tawar sangat diperlukan untuk menunjang fasilitas pengelolaan maupun pelayanan wisata.

\subsection{Indeks Kesesuaian Wisata (IKW)}

Berdasarkan hasil analisis Indeks Kesesuaian Wisata (IKW) pantai didapatkan kategori tingkat kesesuaian wisata pada masing-masing stasiun pengamatan di Pantai Pasir Putih. Kesesuaian wisata tersebut dapat dilihat pada Tabel 13.

\section{Tabel 13}

Indeks Kesesuaian Wisata (IKW) Pantai Pasir Putih

\begin{tabular}{ccc}
\hline Stasisun & IKW $(\%)$ & Kategori Kesesuaian \\
\hline I & 94.23 & Sangat Sesuai \\
II & 96.79 & Sangat Sesuai \\
III & 85.89 & Sangat Sesuai \\
IV & 81.41 & Sangat Sesuai \\
\hline
\end{tabular}

Berdasarkan Tabel 13 dapat dijelaskan bahwa nilai indeks kesesuaian wisata di Pantai Pasir Putih pada stasiun pengamatan I, II, III, dan VI masingmasing sebesar 94.23\%, 96.79\%, 85.89\%, dan 81.41\%. Dengan demikian, kawasan Pantai Pasir Putih termasuk dalam kategori kesesuaian SS (Sangat Sesuai). Sehingga kawasan Pantai Pasir Putih sangat cocok (Sangat Sesuai) untuk dikembangkan menjadi kawasan wisata pantai.

Secara umum kawasan Pantai Pasir Putih memiliki karakteristik yang sama antara stasiun satu dengan yang lainnya. Hal tersebut dapat dilihat dari hasil persentase kesesuaian wisata yang hasilnya tidak terlalu jauh berbeda antara stasiun satu dengan yang lainnya. Dari pengukuran setiap stasiun pengamatan di Pantai Pasir Putih terdapat beberapa parameter yang termasuk kategori S3 (Sesuai Bersyarat) yaitu penutupan lahan pantai dan lebar pantai dan N (Tidak Sesusai) yaitu penutupan lahan pantai.

Nilai indeks kesesuaian wisata ditampilkan dalam bentuk peta kesesuaian untuk kegiatan wisata di kawasan Pantai Pasir Putih. Peta tersebut sebagai petunjuk untuk lokasi yang dijadikan kegiatan wisata (Gambar 2). 


\subsection{Zona Pemanfaatan Kawasan Pantai}

Beberapa kegiatan wisata yang dapat dilakukan di Pantai Pasir Putih adalah Berjemur, Berenang atau bermain air di ombak, dan jalan-jalan atau melihat pemandangan. Semua kegiatan yang dilakukan wisatawan harus tertata (zona pemanfaatan) untuk menjaga kelestarian lingkungan dan menjaga kenyamanan kegiatan wisatawan. Zona kegiatan wisata dapat ditampilkan pada Gambar 3.

Kegiatan berjemur dapat dilakukan pada stasiun I dan II. Pada kawasan ini memiliki tipe pantai yang berpasir, lebar dan kemiringan yang landai sehingga mendukung untuk kegiatan berjemur. Selain itu, Wisatawan yang melakukan wisata berjemur didukung oleh fasilitas tempat berjemur (bed) yang tersedia pada kawasan pantai. Pada stasiun II penutupan lahan pantai seperti pohon kelapa dan lahan terbuka sangat mendukung untuk kegitan berjemur.

Kegiatan berenang atau bermain air di ombak dapat dilakukan pada stasiun I dan II. Hal ini didukung dengan material dasar perairan berupa pasir, kecepatan arus yang sangat sesuai, tidak ditemukan biota berbahaya, serta ketersediaan air tawar yang cukup. Air tawar merupakan elemen penting bagi wisatawan yang melakukan wisata renang atau bermain di Ombak untuk melakukan pembilasan diri setelah melakukan kegiatan wisata.

Kawasan untuk kegiatan jalan-jalan atau melihat pemandangan dapat dilakukan di sepanjang Pantai Pasir Putih yaitu dari stasiun I, II, III, dan IV. Pada kawasan ini memiliki pantai berpasir putih dan kemiringan yang landai. Hal ini didukung karena area pantai yang indah, diapit oleh dua gugusan perbukitan batuan hitam dan juga masih dikelola dengan baik oleh masyarakat sekitar. Jajaran Payung di tepian Pantai membuat pemandangan menjadi lebih indah untuk menikmati panorama pantai Pasir Putih. Namun, pada stasiun III diharapkan berhati-hati melakukan kegiatan wisata jalan-jalan karena merupakan jalur lintas pulang pergi kapal nelayan (Jukung) pada pagi dan sore hari. Perahu (Jukung) tersebut merupakan milik masyarakat yang tingggal disekitar pantai dan berpropesi sebagai nelayan.

Kawasan suci terdapat pada stasiun IV bagian selatan (Gambar 3). Kawasanini merupakan daerah suci karena terdapat Tugu (batu tempat sembhyang bagi umat Hindhu). Penduduk setempat melarang wisatawan melakukan kegiatan wisata di stasiun IV agar kesucian pura tetap terjaga dan terhindar dari bahaya (hal gaib).

\section{Simpulan}

Faktor pembatas indeks kesesuaian wisata (IKW) di Pantai Pasir Putih adalah tutupan lahan pantai dan lebar pantai. Kawasan Pantai Pasir Putih sangat sesuai untuk kegiatan wisata kategori rekreasi pantai dengan nilai Indeks Kesesuaian Wisata (IKW) pada stasiun I, II, III, dan VI masingmasing sebesar $94.23 \%, 96.79 \%, 85.89 \%$, dan $81.41 \%$. Pantai Pasir Putih terbagi menjdi tiga zona pemanfaatan kawasan wisata pantai yaitu: zona berenang, zona berjemur, zona jalan-jalan.

\section{Ucapan terimakasih}

Penulis menyucapkan terima kasih kepada Beasiswa Bidikmisi, Desa Bugbug dan rekan-rekan mahasiswa Fakultas Kelautan dan Perikanan Universitas Udayana atas bantuannya selama penelitian.

\section{Daftar Pustaka}

Ardian., Khodijah., \& Zen, L.W. (2015). Kajian kesesuaian kawasan wisata pantai di Kampung Pasir Panjang Tanjung Siambang Pulau Dompak Kota Tanjung Pinang. UMRAH, 21(5). 36-45.

Buckley, R. (2012). Sustainable tourism: Research and reality. Annals of Tourism Research, 39(2), 528-5

Cahyadinata, I. (2009) Kesesuaian Pengembangan Kawasan Pesisir Pulau Enggano untuk Pariwisata dan Perikanan Tangkap. AGRISEP, 9(2), 168-182.

Fachrul, M. F. (2007). Metode Sampling Bioekologi. Bumi Aksara, 20(15). 168-182.

Hakim, L., Kim, J. E., \& Hong, S. K. (2009). Cultural landscape and ecotourism in Bali Island, Indonesia. Journal of Ecology and environment, 32(1), 1-8.

Henderson, J. C., \& Smith, R. A. (2009). The informal tourism economy at beach resorts: a comparison of Cha-Am and Laguna Phuket in Thailand. Tourism Recreation Research, 34(1), 13-22.

Juliana., Sya'rani, L., \& Zainuri, M. (2013). Kesesuaian dan Daya Dukung Wisata Bahari di Perairan Bandengan Kabupaten Jepara Jawa Tengah. Perikanan dan Kelautan Tropis, 9(1), 1-7.

Law, A., De Lacy, T., Lipman, G., \& Jiang, M. (2016). Transitioning to a green economy: the case of 
tourism in Bali, Indonesia. Journal of Cleaner Production, 111, 295-305.

Muflih, A., Fahrudin, A., \& Wardiatno, Y. (2015). Kesesuaian dan Daya Dukung Wisata Pesisir Tanjung Pasir dan Pulau Untung Jawa. Ilmu Pertanian Indonesia (JIPI), 20(2), 141-149.

Mukhtar, P. D., Rudiyanti, S., \& Purwanti, F. (2016). Analisis Kesesuaian Wisata di Pantai Nyalo [Kawasan Mandeh] Kabupaten Pesisir Selatan, Sumatera Barat. Diponegoro Journal of Maquares, 5(4), 420-426.

Mutmainah, H., Kusumah, G., Altanto, T., \& Ondara, K. (2016). Kajian kesesuaian lingkungan untuk pengembangan wisata di Pantai Ganting, Pulau Simeulue, Provinsi Aceh. DEPIK Jurnal Ilmu-Ilmu Perairan, Pesisir dan Perikanan, 5(1), 19-23.

Pemkab Karangasem. (2012). Peraturan Daerah Kabupaten Karangasem Nomor 17 Tahun 2012 tentang Rencana tata Ruang Wilayah Kabupaten Karangsem Tahun 2012-2032. Lembaran Daerah Kabupaten Karangasem Tahun 2012 Nomor 17. Karangasem, Indonesia: Pemerintah Daerah Kabupaten Karangasem.
Saputra, B. D., Khodijah. 2013. Kesesuaian Perairan Kawal sebagai kawasan wisata pantai di Kabupaten Bintan. UMRAH, 21(1), 1-13.

Sobocinska, A. (2011). Innocence lost and paradise regained Tourism to Bali and Australian perceptions of Asia. History Australia, 8(2), 199-222.

Sutawa, G. K. (2012). Issues on Bali tourism development and community empowerment to support sustainable tourism development. Procedia economics and finance, 4, 413-422.

Yulianda, F. (2007). Ekowisata Bahari Sebagai Alternatif Pemanfaatan Sumberdaya Pesisir Berbasis Konservasi. Makalah Seminar Sehari Pengelolaan Sumberdaya Pesisir dan Laut. Bogor, Indonesia, 21 Februari 2007 (pp. 119-129).

Yulisa, E. N., Johan, Y., Hartono, D. (2016). Analisis kesesuaian dan daya dukung ekowisata pantai kategori rekreasi Pantai Laguna Desa Merpas Kabupaten Kaur. Enggano, 1(1), 97-110.

Yusuf, M. (2007). Kebijakan Pengelolaan Sumberdaya Pesisir dan Laut Kawasan Taman Nasional Karimunjawa Secara Berkelanjutan. Buletin Ekonomi Perikanan, 4(2), 86-98.

(C) 2017 by the authors; licensee Udayana University, Indonesia. This article is an open access article distributed under the terms and conditions of the Creative Commons Attribution license (http://creativecommons.org/licenses/by/3.0/). 